\title{
O TRISTE DESTINO DA ÁREA DE O\&M - II
}

\section{Miguel P. Caldas}

Mestre e Doutor em Administração de Empresas pela EAESP/FGV, Professor do Departamento de Administração Geral e Recursos Humanos da EAESP/FGV e Consultor de Empresas.

E-mail: mcaldas@fgvsp.br

\section{RESUMO}

Este artigo corresponde à segunda parte de uma pesquisa que investiga a evolução da função e da carreira de Organização e Métodos (O\&M) nas empresas no Brasil desde 1985. Este estudo procura verificar empiricamente até que ponto a carreira e o profissional de O\&M sofreram ou não, como sugerem alguns autores, um declínio em relação a outras áreas afins, tais como recursos humanos, informática ou qualidade. Para tanto, levantou-se a oferta de posições em O\&M (comparada com essas outras áreas), via evolução da quantidade, da qualidade e do prestígio de anúncios de empregos em um jornal paulista, entre 1985 e 1996. Os resultados desse levantamento foram cruzados com a outra parte da pesquisa, realizada por meio de questionários, sobre o destino da função de O\&M em 60 organizações no estado de São Paulo. 0 artigo também sugere como o processo de transformação da carreira de O\&M pode ser relevante para 0 entendimento das mudanças pelas quais outras carreiras administrativas passam nos dias de hoje.

\section{ABSTRACT}

This article is the second part of a study investigating what happened to the Organization and Methods (O\&M) function and career in Brazilian organizations since 1985. This research aims to empirically verify whether or not the O\&M career and professional have suffered, as some authors have argued, a significant decline as compared to related areas, such as human resources, information technology and quality. For that purpose, the study analyzed the evolution of job offers for O\&M positions (compared to that of other areas), measuring the volume, quality and prestige of job positions posted in a large circulation newspaper in São Paulo, between 1985 and 1996. The data obtained in such study was combined with the results in the first part of the research, which came from questionnaires about the destiny of the O\&M department gathered in 60 organizations in the state of São Paulo. The study also suggests how the understanding of the transformation process of the O\&M career may be relevant for the comprehension of those changes that other managerial careers are going through in today's organizations.

PALAVRAS-CHAVE

O\&M, Organização e Métodos, carreira, mudança organizacional.

KEY WORDS

O\&M, Organization and Methods, career, organizational change. 


\section{INTRODUÇÃO}

O profissional de $\mathrm{O} \& \mathrm{M}$, bem como a área em que trabalhava, foi uma referência comum na maioria de nossas organizações durante boa parte dos anos $70 \mathrm{e}$ 80. Tal como, na segunda metade dos anos 80 e no início dos anos 90, foi difícil ficar alheio ao movimento de Qualidade Total nas empresas brasileiras e da mesma forma que, nos anos 90, não se pode ficar isento dos processos de Reengenharia, durante boa parte dos anos 70 e 80, a maior parte de nós, em empresas brasileiras, não conseguia ficar por muito tempo distante do "pessoal de O\&M".

Uma carreira de O\&M nasceu e se desenvolveu. Associações foram criadas pelos profissionais ligados à atividade. Congressos, seminários e encontros anuais foram organizados. Uma cadeira de "Organizações e Métodos" - ou de "Sistemas e Métodos" - foi oficializada no currículo do curso de administração, e o Conselho Federal de Educação ratificou-a como cadeira obrigatória no currículo mínimo já na década de 90 . Em outras palavras, o O\&M, como função, atividade e carreira, foi plenamente institucionalizado nas empresas brasileiras.

Entretanto, algo parece ter acontecido nesse ambiente em um espaço de menos de 20 anos. O O\&M não é mais tão facilmente encontrado nas empresas. Aparentemente, as associações e os congressos não são tão abundantes como antes. E o "profissional de O\&M", esse velho conhecido, não é mais visto com tanta freqüência nas folhas de pagamento de nossas organizações quanto era há 15 ou 20 anos.

$\mathrm{Na}$ academia, quase nada tem sido estudado ou escrito a respeito. Uma das exceções foi o Prof. José Ernesto L. Gonçalves, que, em um artigo na RAE Light, em 1995, escreveu a respeito da transformação do O\&M no Brasil, argumentando sobre a pulverização de suas atividades para outras áreas (segundo ele, para a área de informática), sobre a sua substituição por ferramentas automatizadas ou por prestadores de serviços externos ou ainda sobre a sua simples eliminação em muitas empresas (Gonçalves, 1995).

O presente artigo está incluso numa pesquisa mais abrangente sobre o O\&M no Brasil, que possui três partes, para três objetos de estudo: a função, as atividades e a carreira de Organização e Métodos nas empresas no Brasil. Entende-se como função de O\&M o(s) departamento(s) ou órgão(os) formal(is) que, dentro de uma organização em particular, desempenha(m) atividades tipicamente de Organização e Métodos. Por ati- vidades de O\&M, define-se o conjunto de ações e atribuições organizacionais que, comumente - porém não necessariamente -, são de responsabilidade de áreas de O\&M, sendo as mais comuns: a) desenho, racionalização e normatização de processos e procedimentos organizacionais; b) desenho, formalização e mudança

\section{O "profissional de O\&M" não é}

\section{mais visto com tanta freqüência}

\section{nas folhas de pagamento de}

\section{nossas organizações quanto}

\section{era há 15 ou 20 anos.}

da estrutura organizacional; c) desenho, racionalização e normatização de formulários; e d) normatização e racionalização do uso do espaço físico e layout na empresa. Por carreira de O\&M, entende-se a trilha de progressão profissional seguida por aqueles indivíduos que optaram por dedicar-se às atividades de O\&M nas empresas.

Em função dos seus limites físicos, este artigo concentra-se apenas na terceira parte do estudo, cujo objeto é a carreira de O\&M nas empresas no Brasil. Essencialmente, o objetivo desta parte da pesquisa é investigar até que ponto o O\&M - como carreira - sofreu ou não um declínio em relação a outras áreas afins (tais como recursos humanos, informática ou qualidade) no Brasil entre 1985 e 1996. Entende-se declínio de carreira como a queda de atratividade daquela trilha como opção profissional.

A compreensão da evolução da carreira de O\&M se justifica por diversos motivos. Primeiro, porque entender o sentido e os condicionantes da mudança da função e da carreira de O\&M parece ser emblemático da forma em que estruturas e carreiras têm sido transformadas na prática organizacional brasileira. Segundo, porque a forma e o padrão evolutivo dessa mudança na carreira de O\&M podem dar a profissionais e estudiosos de recursos humanos uma pista importante de como competências organizacionais e individuais têm evoluído em nossas organizações, o que capacita o RH a ajudar tanto as organizações quanto os profissionais a antecipar essas instabilidades e conviver com elas.

O presente artigo está organizado da seguinte forma: nesta "Introdução", procura-se delimitar os obje- 
tivos e o escopo da pesquisa. Na seção seguinte ("Formulação das hipóteses"), busca-se esclarecer as premissas e hipóteses que a pesquisa procurou testar empiricamente. Na terceira seção ("Metodologia da pesquisa"), o objetivo é discutir a metodologia utilizada para o estudo, incluindo a modelagem da pesquisa e a explicitação das variáveis sob análise. A quarta seção ("Resultados do estudo") sintetiza os achados do

\section{A demanda por posiçóes}

\section{de $0 \& M$ caiu mais do que a}

\section{de todas as outras áreas em}

\section{termos relativos.}

estudo e o resultado do teste de hipóteses. Na quinta seção ("Análise”), a intenção é, em primeiro lugar, discutir alguns dos fatores que condicionaram os eventos retratados na pesquisa, em segundo lugar, sugerir as perspectivas futuras da carreira e do profissional de O\&M e, em terceiro lugar, analisar as lições que o processo evolutivo da carreira de O\&M deixa para todos nós, nas organizações. Por fim, na última seção ("Conclusões"), procura-se resumir os resultados do estudo.

\section{FORMULAÇÃO DAS HIPÓTESES}

De forma geral, a pesquisa mais abrangente na qual este estudo está inserido previa que, desde os prósperos anos 70 e 80 , o O\&M teria passado por um processo radical de questionamento e de transformação, até seu virtual desaparecimento nas empresas atuais. Mais especificamente, o estudo analisou essa premissa dedicando-se ao teste de três conjuntos de hipóteses (uma para cada objeto). No presente estudo, entretanto, só analisaremos as hipóteses relativas à carreira de O\&M. Esse (terceiro) conjunto de hipóteses propunha previsões sobre a atratividade da carreira de O\&M nesse presumido contexto de transformação e declínio de O\&M.

3. Em função da transformação da função de O\&M, a demanda e o prestígio de seus profissionais devem ter caído significativamente, assim como a sua fidelidade à carreira.

Em outras palavras, a Hipótese 3 e suas subipóteses prevêem que o suposto declínio da função de O\&M teria provocado uma diminuição significativa da atra- tividade da carreira de O\&M, medida a) por uma queda da demanda de empresas por profissionais especializados nesse tipo de função; b) pela queda no prestígio da área e de seus profissionais nas empresas em que atuam; e c) pela migração de muitos desses profissionais para outras carreiras, tanto em outras áreas da empresa quanto fora da organização.

3a. A demanda e o prestígio de profissionais de O\&M devem ter caído mais desde 1985 do que os de outras áreas, como recursos humanos, informática ou qualidade.

3b. Tipicamente, profissionais de O\&M devem ter sido absorvidos por estas áreas de migração das atividades tradicionais de O\&M: informática, recursos humanos, qualidade, engenharia de processos, entre as áreas funcionais internas, e consultoria, entre as funções externas.

3c. Mais profissionais dispensados em processos de extinção de O\&M devem ter mudado ou expandido suas áreas de atuação do que aqueles que obtiveram nova colocação em $O \& M$ em outras empresas.

A forma pela qual se pretendeu, neste estudo, testar tais hipóteses no contexto brasileiro será discutida na próxima seção.

\section{METODOLOGIA DA PESQUISA}

O segmento da pesquisa sintetizado no presente artigo compreendeu um levantamento da oferta comparada de empregos em O\&M e em outras áreas entre 1985 e 1996, tendo como amostra um jornal paulista de grande circulação. O objetivo do levantamento foi comparar a atratividade e o prestígio entre a função de O\&M e outras "concorrentes" (em mão-de-obra) no período pesquisado, por meio da análise da evolução de anúncios de empregos veiculados naquele jornal no referido período.

As premissas metodológicas nesse tipo de pesquisa merecem ser destacadas. Embora se admita que a oferta de empregos em classificados não seja um indicador preciso do nível de oferta de emprego de uma área - pelo contrário, está longe disso -, assumiu-se que seria um indicador razoável (proxi) da atratividade e do prestígio de uma carreira (no caso, a de O\&M) se pudesse ser usado um procedimento comparado e longitudinal entre essa área e outras que concorressem com ela em atração de mão-de-obra. Isso implica aceitar duas premissas conceituais que justificariam esse caminho metodológico: primeiro, é preciso 
admitir que a variação da oferta de empregos esteja ligada à variação na atratividade - e, por decorrência, no prestígio comparado - dessa área como escolha para mão-de-obra qualificada em busca de uma carreira. Em outras palavras, quanto mais aumenta, ao longo do tempo (análise longitudinal), a oferta de emprego de uma área em relação a outras afins (análise comparada), maior se tornam a atratividade e o prestígio dessa área como opção de carreira. Segundo, é necessário aceitar que, embora a oferta de emprego em jornais seja muito inferior à oferta total de emprego, uma deve variar em conformidade com a outra, isto é, se a oferta de posições de emprego em O\&M por meio de jornais cai ao longo do tempo em relação à oferta de empregos em outras áreas, é muito provável que o mesmo tenha acontecido com a oferta total de empregos dessas áreas. O presente estudo aceitou essas premissas e utilizou, portanto, o método de medir comparativamente atratividade e prestígio de O\&M em relação a outras áreas pelo acompanhamento da oferta de emprego em um jornal de grande circulação no período em questão.

A coleta foi feita pela contagem dos anúncios de emprego de um mesmo jornal nas mesmas edições de 1985 a $1996^{1}$ para quatro níveis de posição (direção, gerência, técnico/supervisão e operacional) e para quatro áreas funcionais, como grupos de controle: O\&M (objeto focal), recursos humanos, qualidade e informática. A amostra final foi composta por quatro observações em cada ano pesquisado, obtidas nas edições correspondentes dos classificados de domingo de $O$ Estado de S. Paulo, distribuídas consistentemente ao longo do ano, ou seja, para cada ano, a contagem foi feita para todas as funções e níveis pesquisados nas edições dos classificados: a) no quarto domingo de cada mês de março; b) no segundo domingo de cada mês de junho; c) no terceiro domingo de cada mês de setembro; e d) no primeiro domingo de cada mês de dezembro. Nos anos em que essas edições caíram em feriados, o que poderia ter prejudicado sua representatividade, a edição do domingo imediatamente anterior ou posterior foi usada como substituta.

No que tange ao teste de hipóteses, ou mais especificamente da Hipótese 3a, o método utilizado na pesquisa envolve: a) a comparação do número de anúncios veiculados no período para cada área testada, o que servirá como indicador quantitativo da evolução da demanda de emprego nessas funções; e b) a comparação da importância relativa (indicador qualitativo) desses anúncios para cada área. Para o teste qua- litativo, o método utilizado assumiu que o espaço comprado para anúncios de emprego de uma área em relação às demais é um indicador adequado da importância relativa dessa área em relação às demais. Em outras palavras, o método partiu da premissa de que, quanto maior o espaço de jornal comprado por empresas para anunciar ofertas de emprego para uma determinada área, maior deve ser a valorização daquela área funcional em relação às demais e, longitudinalmente, maior deve ser a indicação de sua atratividade como carreira. Assim, o método previu a divisão dos anúncios para cada área em espaço de jornal utilizado: anúncios de destaque (em geral, um quarto de página), anúncios-padrão (que comumente ocupam de metade a um terço do espaço dos anúncios de destaque) e microanúncios (de três ou quatro linhas em colunas de classificados). Comparando-se esses números com o total de espaço de classificados de emprego em cada edição, obteve-se a distribuição da importância relativa do $\mathrm{O} \& \mathrm{M}$ em relação às demais áreas nesse quesito.

Como um todo, as principais variáveis coletadas em cada observação desse segmento da pesquisa foram as apresentadas no Quadro 1.

Quadro 1 - Variáveis coletadas

\begin{tabular}{ll} 
Variáveis dependentes & Variáveis independentes \\
\hline - Número de posições & - Número de posições \\
ofertadas para a área de & ofertadas para a área de \\
O\&M por nível (direção, & RH por nível (direção, \\
gerência, técnico/ & gerência, técnico/ \\
supervisão e & supervisão e operacional) \\
operacional) & - Número de posições \\
Espaço dedicado aos & ofertadas para a área de \\
anúncios (como medida & qualidade por nível \\
de prestígio da posição) & (direção, gerência, \\
de vagas de O\&M em & técnico/supervisão e \\
relação ao total de & operacional) \\
espaço disponível na & - Número de posições \\
edição e às demais & ofertadas para a área de \\
funções (grupos de & informática por nível \\
controle) & (direção, gerência, \\
& técnico/supervisão e \\
operacional)
\end{tabular}




\section{RESULTADOS DO ESTUDO}

No que se refere à primeira subipótese, que previa que a demanda e o prestígio de profissionais de O\&M teriam caído mais desde 1985 do que os de outras áreas, os resultados corroboraram a Hipótese 3a, ou seja, de fato, o O\&M - como carreira e escolha de especialização profissional - mostrou claro declínio, tanto em oferta de empregos quanto em prestígio, em relação às demais áreas funcionais pesquisadas.

Se medida a oferta relativa de empregos entre o $\mathrm{O} \& \mathrm{M}$ e as áreas de controle, como mostra a Tabela 1 , a demanda por posições de O\&M caiu mais do que a de todas as outras áreas em termos relativos.
Embora o número de anúncios tenha diminuído em todas as áreas (o que, cabe lembrar, não indica necessariamente uma queda total na oferta de empregos, mas o declínio desse tipo de mídia) no período analisado, a área de informática foi a única que conseguiu manter uma média mais alta e constante de ofertas. A área de qualidade foi a única que cresceu em termos relativos, apesar de manter-se pouco significativa no total. A área de $\mathrm{RH}$, tal como a de O\&M, sofreu uma queda na oferta de empregos no período; entretanto, não só tal queda foi menos grave do que a do $\mathrm{O} \& \mathrm{M}$, como sua recuperação em termos relativos, ao longo do tempo, foi muito melhor do que a do O\&M.

Tabela 1 - Distribuição do número de anúncios de emprego por área e níve

\begin{tabular}{|c|c|c|c|c|c|c|c|c|c|c|c|c|c|c|}
\hline & & 1985 & 1986 & 1987 & 1988 & 1989 & 1990 & 1991 & 1992 & 1993 & 1994 & 1995 & 1996 & Total \\
\hline \multirow{5}{*}{$\begin{array}{c}\text { Área } \\
\text { de } \\
\text { O\&M }\end{array}$} & Diretores & 0 & 1 & 0 & 2 & 1 & 1 & 0 & 0 & 1 & 0 & 0 & 0 & 6 \\
\hline & Gerentes & 2 & 5 & 7 & 1 & 2 & 1 & 1 & 0 & 0 & 2 & 0 & 1 & 22 \\
\hline & Chefes & 4 & 96 & 76 & 49 & 88 & 36 & 18 & 8 & 10 & 9 & 3 & 7 & 404 \\
\hline & Analistas & 81 & 96 & 76 & 49 & 88 & 36 & 18 & 8 & 10 & 9 & 3 & 7 & 481 \\
\hline & Total & 87 & 198 & 159 & 101 & 179 & 74 & 37 & 16 & 21 & 20 & 6 & 15 & 913 \\
\hline \multirow{5}{*}{$\begin{array}{c}\text { Área } \\
\text { de } \\
\text { RH }\end{array}$} & Diretores & 0 & 14 & 3 & 7 & 11 & 6 & 4 & 4 & 3 & 7 & 5 & 2 & 66 \\
\hline & Gerentes & 9 & 4 & 7 & 12 & 9 & 6 & 2 & 1 & 0 & 3 & 7 & 8 & 68 \\
\hline & Chefes & 4 & 20 & 16 & 25 & 32 & 10 & 13 & 3 & 7 & 5 & 15 & 5 & 155 \\
\hline & Analistas & 21 & 20 & 16 & 25 & 32 & 10 & 13 & 3 & 7 & 5 & 15 & 5 & 172 \\
\hline & Total & 34 & 58 & 42 & 69 & 84 & 32 & 32 & 11 & 17 & 20 & 42 & 20 & 461 \\
\hline \multirow{5}{*}{$\begin{array}{c}\text { Área } \\
\text { de } \\
\text { infor- } \\
\text { mática }\end{array}$} & Diretores & 0 & 3 & 2 & 4 & 7 & 4 & 1 & 7 & 0 & 11 & 6 & 2 & 47 \\
\hline & Gerentes & 8 & 6 & 9 & 4 & 11 & 10 & 10 & 1 & 10 & 11 & 2 & 4 & 86 \\
\hline & Chefes & 11 & 395 & 415 & 361 & 589 & 412 & 209 & 123 & 197 & 346 & 329 & 151 & 3.538 \\
\hline & Analistas & 378 & 395 & 415 & 361 & 589 & 412 & 209 & 123 & 197 & 346 & 329 & 151 & 3.905 \\
\hline & Total & 397 & 799 & 841 & 730 & 1.196 & 838 & 429 & 254 & 404 & 714 & 666 & 308 & 7.576 \\
\hline \multirow{5}{*}{$\begin{array}{c}\text { Área } \\
\text { de } \\
\text { quali- } \\
\text { dade }\end{array}$} & Diretores & 0 & 1 & 0 & 0 & 0 & 3 & 2 & 1 & 4 & 5 & 3 & 8 & 27 \\
\hline & Gerentes & 2 & 0 & 0 & 0 & 0 & 0 & 5 & 0 & 0 & 3 & 2 & 5 & 17 \\
\hline & Chefes & 2 & 2 & 1 & 2 & 3 & 2 & 3 & 0 & 2 & 10 & 23 & 7 & 57 \\
\hline & Analistas & 8 & 2 & 1 & 2 & 3 & 2 & 3 & 0 & 2 & 10 & 23 & 7 & 63 \\
\hline & Total & 12 & 5 & 2 & 4 & 6 & 7 & 13 & 1 & 8 & 28 & 51 & 27 & 164 \\
\hline \multirow{5}{*}{$\begin{array}{c}\text { Total } \\
\text { geral } \\
\text { (áreas) }\end{array}$} & O\&M & 87 & 198 & 159 & 101 & 179 & 74 & 37 & 16 & 21 & 20 & 6 & 15 & 913 \\
\hline & $\mathrm{RH}$ & 34 & 58 & 42 & 69 & 84 & 32 & 32 & 11 & 17 & 20 & 42 & 20 & 461 \\
\hline & Informática & 397 & 799 & 841 & 730 & 1.196 & 838 & 429 & 254 & 404 & 714 & 666 & 308 & 7.576 \\
\hline & Qualidade & 12 & 5 & 2 & 4 & 6 & 7 & 13 & 1 & 8 & 28 & 51 & 27 & 164 \\
\hline & Total & 530 & 1.060 & 1.044 & 904 & 1.465 & 951 & 511 & 282 & 450 & 782 & 765 & 370 & 9.114 \\
\hline \multirow{5}{*}{$\begin{array}{c}\text { Total } \\
\text { geral } \\
\text { (níveis) }\end{array}$} & Diretores & 0 & 19 & 5 & 13 & 19 & 14 & 7 & 12 & 8 & 23 & 14 & 12 & 146 \\
\hline & Gerentes & 21 & 15 & 23 & 17 & 22 & 17 & 18 & 2 & 10 & 19 & 11 & 18 & 193 \\
\hline & Chefes & 21 & 513 & 508 & 437 & 712 & 460 & 243 & 134 & 216 & 370 & 370 & 170 & 4.154 \\
\hline & Analistas & 488 & 513 & 508 & 437 & 712 & 460 & 243 & 134 & 216 & 370 & 370 & 170 & 4.621 \\
\hline & Total & 530 & 1.060 & 1.044 & 904 & 1.465 & 951 & 511 & 282 & 450 & 782 & 765 & 370 & 9.114 \\
\hline
\end{tabular}


Na verdade, a área de O\&M nunca mais conseguiu recuperar sua posição anterior em termos de oferta de emprego, seja em termos absolutos, seja em relação às demais áreas analisadas. Essas diferenças podem ser mais bem percebidas ao visualizar-se a evolução de ofertas sem a área de informática, como mostra a Figura 1.

Se a oferta de empregos na área de O\&M sofreu queda significativa no período, o que já poderia indicar queda de prestígio da área, dois tipos de evidência desse segmento da pesquisa reforçam a queda da atratividade do O\&M como carreira. Por um lado, vê-se que o tipo de cargo ofertado em O\&M tem sido cada vez menos importante (novamente, em relação às demais áreas usadas como grupo de controle); por outro, percebe-se que os anúncios são cada vez menos destacados em relação às demais áreas, o que é também um indicador da queda da atratividade da área nas empresas.

Quanto à primeira evidência, a Figura 2 mostra como o número de ofertas para gerente e diretor teve evolução mais negativa em O\&M do que em todas as outras áreas analisadas.

A segunda evidência encontrada da queda de pres- tígio do O\&M é a queda relativa no espaço de classificados comprado pelas empresas para o O\&M em relação ao espaço comprado para ofertas nas demais áreas (ver Tabela 2). A Figura 3 evidencia que as ofertas de emprego veiculadas em jornal para o O\&M têm sido cada vez menos destacadas.

Pela evolução de ofertas, percebe-se que apenas a área de informática conseguiu resistir (ou recuperarse) à queda de espaço comprado no período. Quanto ao O\&M, nota-se que, embora o espaço alocado tenha caído como os demais, a queda relativa é mais grave e de menor recuperação que as outras áreas funcionais.

Observações interessantes a esse respeito podem ser feitas retirando-se a área de informática e focandose apenas a proporção de anúncios de destaque de cada área em relação ao total, como mostra a Figura 4.

O gráfico da Figura 4 mostra que, embora o O\&M preserve uma parcela surpreendente de anúncios de destaque em relação, por exemplo, ao $\mathrm{RH}$, essa proporção é declinante ao longo do tempo. O contrário acontece, por exemplo, com a área de qualidade, que ocupa espaço crescente de ofertas e cujo prestígio de fato parece ascendente nas empresas nos últimos anos.

Figura 1 - Evolução da oferta de empregos por área (excluindo informática)

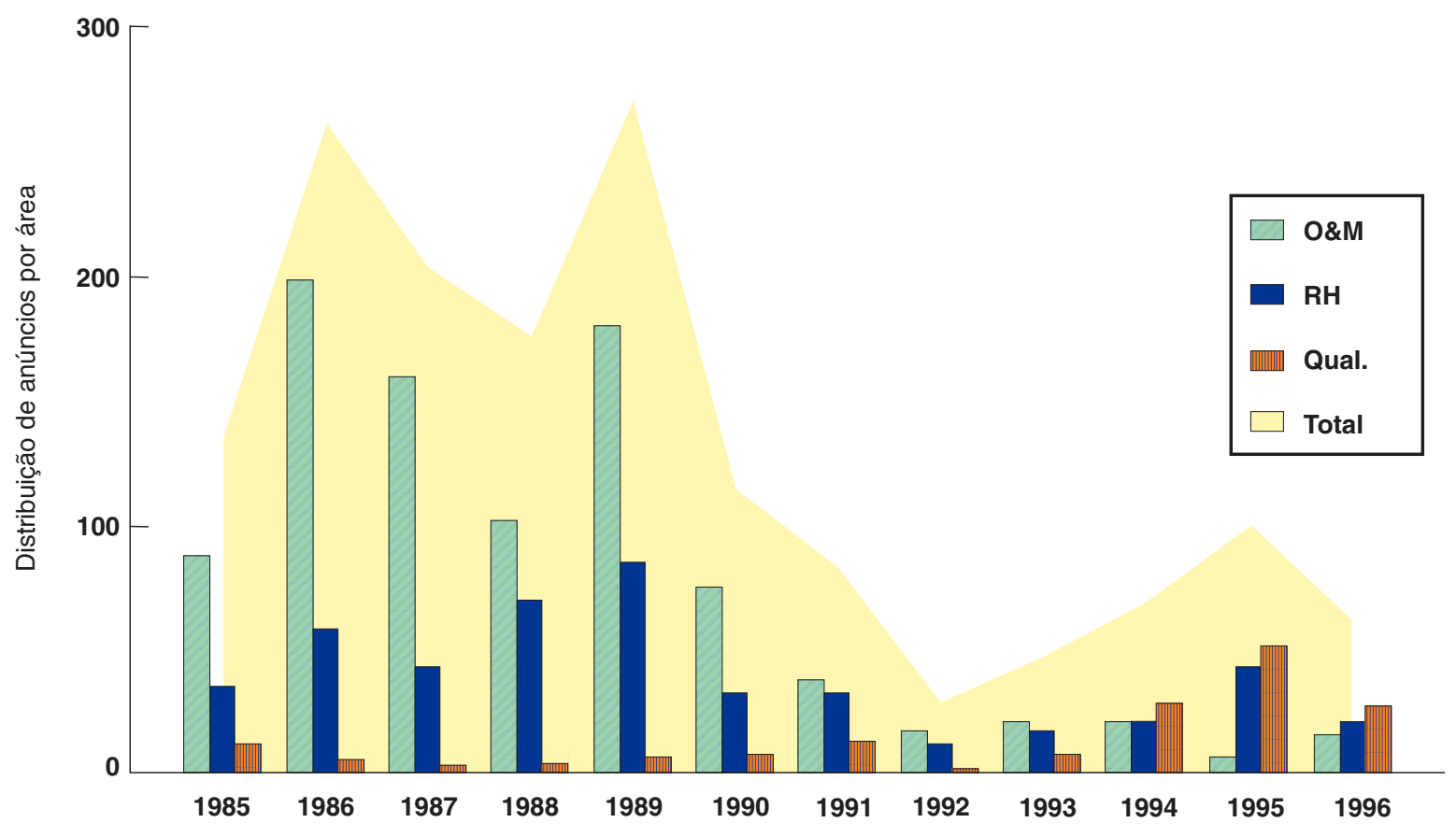


Figura 2 - Evolução das ofertas para diretores e gerentes por área

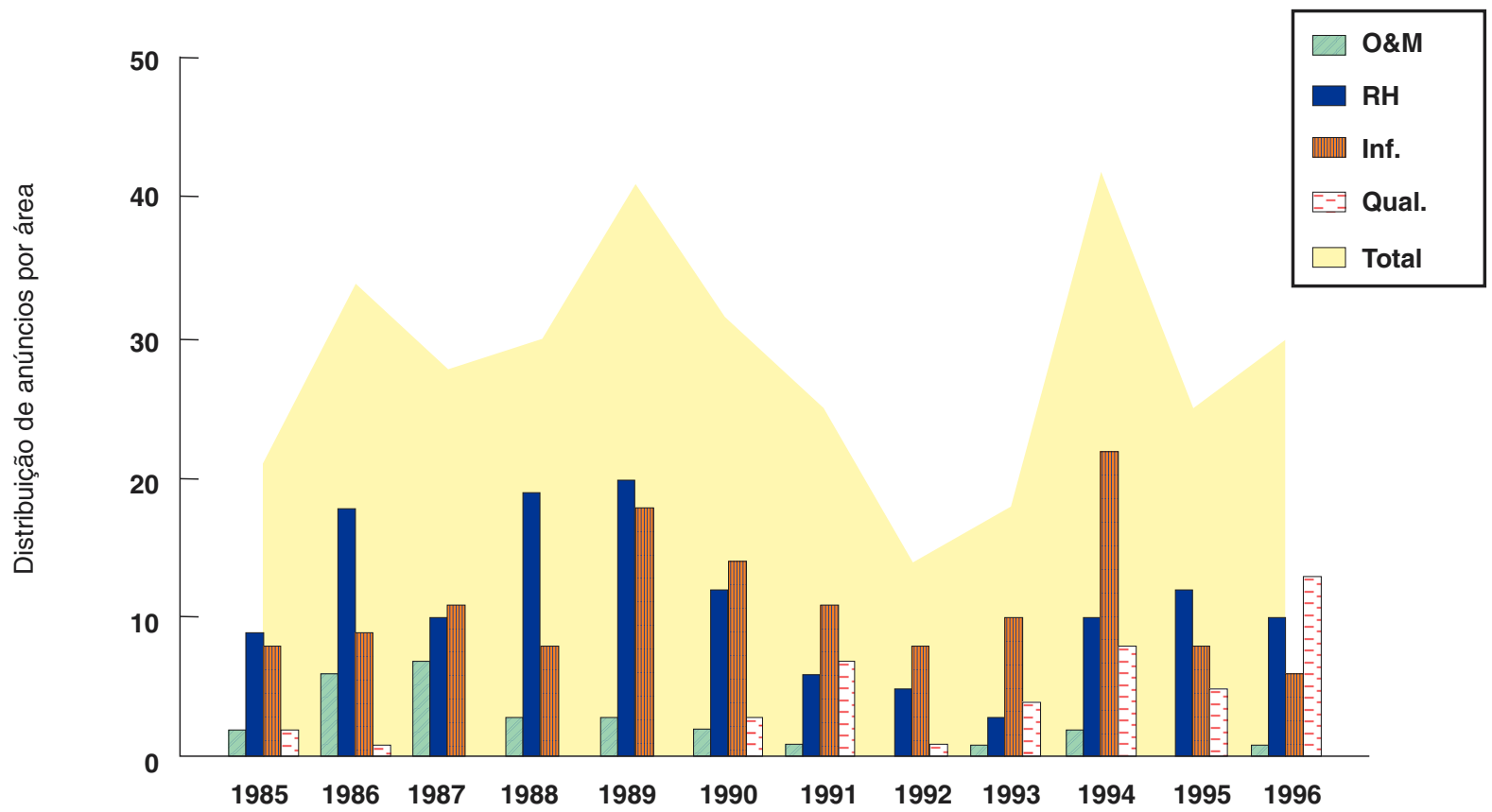

Figura 3 - Evolução da área de jornal comprada para ofertas por área IMPORTÂNCIA RELATIVA DOS ANÚNCIOS POR ÁREA

(Distribuição dos anúncios de destaque por área)

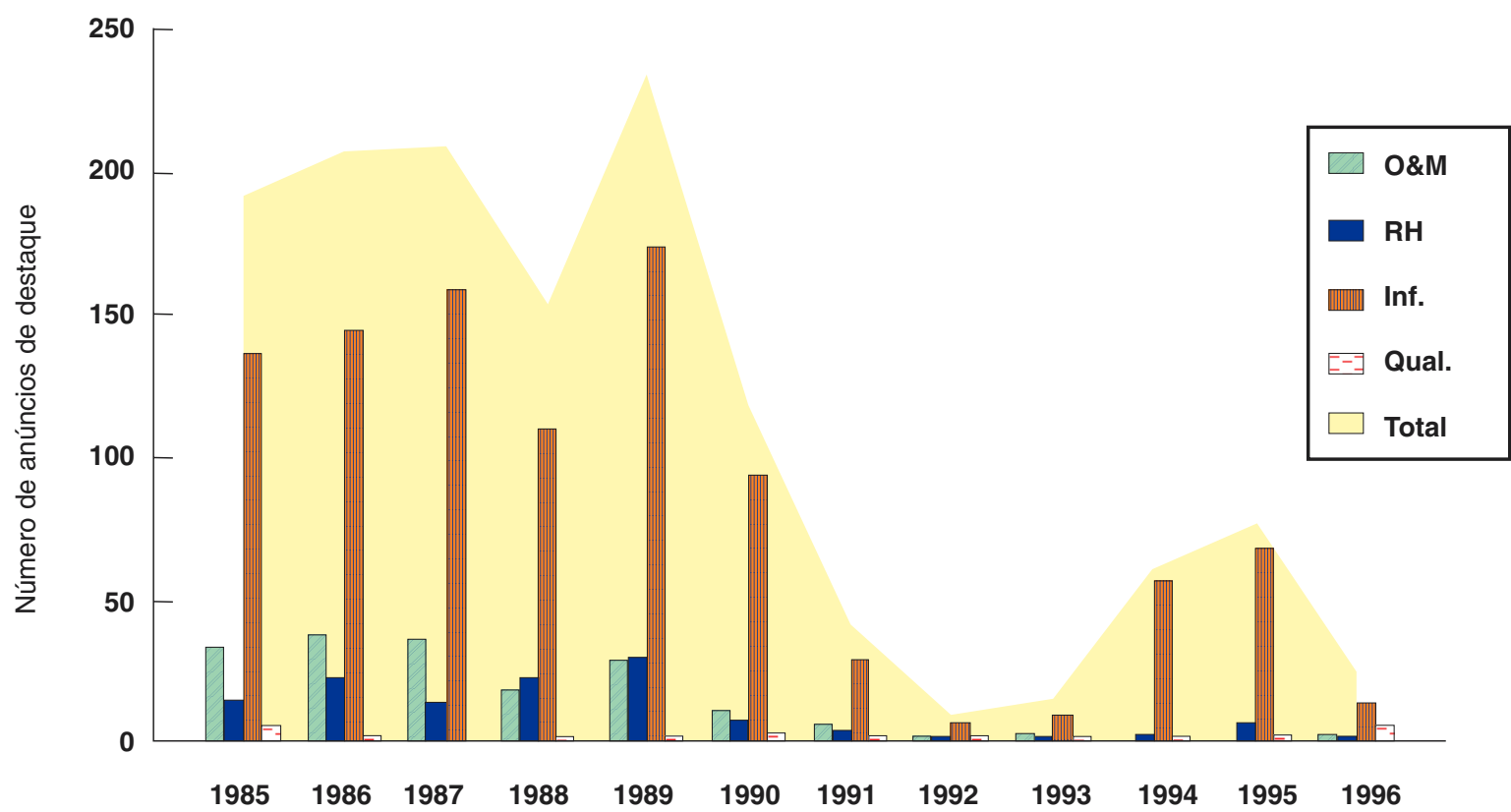


Alguns dados dos demais segmentos da pesquisa (não sintetizados neste artigo) também evidenciaram essa queda de prestígio da área de O\&M em relação às demais áreas do grupo de controle. Segundo as 60 organizações que responderam a um questionário detalhado sobre o destino da função e das atividades de O\&M de 1985 a 1997, quando a área de O\&M não deixou de existir no período, ou ela diminuiu em tamanho (55\% das respondentes), ou diminuiu também em importância ( $88 \%$ das respondentes), se esta for medida pelo nível de reporte hierárquico da área dentro da organização. Ainda entre as empresas respondentes, quando a área de O\&M foi extinta ou incorporada por outras áreas, em geral, as atividades de O\&M ou foram terceirizadas para agentes ou consultores externos, ou foram assumidas pelas áreas de informática, recursos humanos e qualidade. Essas informações também podem dar indícios importantes a respeito da migração do profissional de O\&M nesse período.

As Hipóteses 3b e 3c não puderam ser testadas satisfatoriamente, em função do baixo nível de resposta para a "questão 5N" do roteiro de entrevistas. Pesquisas futuras poderão investigar o fluxo migratório dos profissionais que antes focavam suas carreiras em funções de O\&M. Os resultados desta pesquisa, no entanto, sugerem que a emigração deve ter ocorrido não só em função do declínio do O\&M nas empresas mas também da queda da oferta relativa de empregos em O\&M e que tal migração deve ter-se dado em especial para as áreas de informática, recursos humanos e qualidade, no que tange ao âmbito interno das organizações, e de consultoria, no que toca ao âmbito externo.

\section{ANÁLISE}

Os resultados da pesquisa (em especial se comparados com os resultados dos demais segmentos da pesquisa não detalhados aqui) trazem evidência empírica de que a carreira de O\&M mostrou claro declínio no período: o profissional de O\&M parece ter perdido atratividade e prestígio quando comparado ao de outras áreas funcionais.

Pode-se argumentar que a grande transformação da função e da carreira de O\&M nos últimos anos deve ter ocorrido por uma série de fatores condicionantes distintos combinados, em especial: as diversas mudan-

Tabela 2 - Distribuição da importância (em espaço) de anúncios por área

\begin{tabular}{|c|c|c|c|c|c|c|c|c|c|c|c|c|c|c|}
\hline & & 1985 & 1986 & 1987 & 1988 & 1989 & 1990 & 1991 & 1992 & 1993 & 1994 & 1995 & 1996 & Total \\
\hline \multirow{4}{*}{ O\&M } & Destaque & 34 & 38 & 36 & 19 & 29 & 12 & 6 & 1 & 3 & 0 & 0 & 3 & 181 \\
\hline & Padrão & 28 & 47 & 38 & 21 & 51 & 19 & 4 & 5 & 6 & 9 & 1 & 2 & 231 \\
\hline & Micro & 25 & 17 & 9 & 12 & 11 & 7 & 9 & 2 & 2 & 2 & 2 & 3 & 101 \\
\hline & Total & 87 & 102 & 83 & 52 & 91 & 38 & 19 & 8 & 11 & 11 & 3 & 8 & 513 \\
\hline \multirow{4}{*}{ RH } & Destaque & 15 & 23 & 14 & 23 & 30 & 8 & 5 & 1 & 1 & 3 & 7 & 2 & 132 \\
\hline & Padrão & 16 & 6 & 9 & 17 & 18 & 11 & 6 & 5 & 6 & 8 & 9 & 11 & 122 \\
\hline & Micro & 3 & 9 & 3 & 5 & 5 & 3 & 8 & 3 & 3 & 4 & 11 & 4 & 61 \\
\hline & Total & 34 & 38 & 26 & 45 & 53 & 22 & 19 & 9 & 10 & 15 & 27 & 17 & 315 \\
\hline \multirow{4}{*}{$\begin{array}{l}\text { Infor- } \\
\text { mática }\end{array}$} & Destaque & 136 & 144 & 158 & 110 & 173 & 94 & 29 & 7 & 10 & 57 & 68 & 14 & 1.000 \\
\hline & Padrão & 149 & 167 & 168 & 162 & 224 & 166 & 83 & 60 & 111 & 189 & 161 & 96 & 1.736 \\
\hline & Micro & 112 & 93 & 101 & 97 & 210 & 166 & 108 & 64 & 86 & 122 & 108 & 47 & 1.314 \\
\hline & Total & 397 & 404 & 427 & 369 & 607 & 426 & 220 & 131 & 207 & 368 & 337 & 157 & 4.050 \\
\hline \multirow{4}{*}{$\begin{array}{l}\text { Quali- } \\
\text { dade }\end{array}$} & Destaque & 6 & 2 & 0 & 1 & 1 & 3 & 1 & 1 & 1 & 1 & 2 & 6 & 25 \\
\hline & Padrão & 2 & 1 & 1 & 1 & 2 & 2 & 7 & 0 & 3 & 10 & 10 & 7 & 46 \\
\hline & Micro & 4 & 0 & 0 & 0 & 0 & 0 & 2 & 0 & 2 & 7 & 16 & 7 & 38 \\
\hline & Total & 12 & 3 & 1 & 2 & 3 & 5 & 10 & 1 & 6 & 18 & 28 & 20 & 109 \\
\hline \multirow{4}{*}{$\begin{array}{l}\text { Total } \\
\text { geral }\end{array}$} & Destaque & 191 & 207 & 208 & 153 & 233 & 117 & 41 & 10 & 15 & 61 & 77 & 25 & 1.338 \\
\hline & Padrão & 195 & 221 & 216 & 201 & 295 & 198 & 100 & 70 & 126 & 216 & 181 & 116 & 2.135 \\
\hline & Micro & 144 & 119 & 113 & 114 & 226 & 176 & 127 & 69 & 93 & 135 & 137 & 61 & 1.514 \\
\hline & Total & 530 & 547 & 537 & 468 & 754 & 491 & 268 & 149 & 234 & 412 & 395 & 202 & 4.987 \\
\hline
\end{tabular}


ças nos modelos de gestão, o desenvolvimento da Tecnologia de Informação (TI), o incremento de competitividade e, por fim, os diversos elementos da autodeterioração do $O \& M$ tradicional. Embora não caiba aqui discutir tais fatores alongadamente, com certeza, eles não podem ser vistos atuando separadamente: todos são tão interdependentes que sua separação só se justifica por motivos didáticos.

As mudanças nos modelos de gestão envolvem as drásticas mudanças no design organizacional (Nadler e Gerstein, 1994; Mintzberg, 1995) que transformaram completamente tanto o desenho do trabalho individual (empowerment, polivalência, integração sociotécnica do trabalho etc.) quanto o desenho da organização como um todo (foco nas necessidades externas, base em unidades semi-autônomas, clareza na definição de metas, correção de desvios na origem etc.). Na maioria das vezes, o profissional de O\&M tendia a ficar indiferente a tão radicais mudanças nos modelos de organização do trabalho e ainda procurava desenhar ou racionalizar o trabalho usando conceitos tradicionais da organização fordista; muito poucas áreas e profissionais da função conseguiram antever ou reagir a tempo a tamanhas transformações.

O segundo fator foi o desenvolvimento da Tecnologia de Informação (TI), que influenciou o profissi- onal de O\&M em ao menos três dimensões: a) tornando obsoletas boa parte das necessidades que viabilizavam a função de $\mathrm{O} \& \mathrm{M}$; b) dando ao usuário acesso direto a informação e a ferramentas de apoio, as quais antes dependiam do O\&M; e c) dando importância e poder à área de informática nas organizações, o que permitiu que muitos profissionais de O\&M fossem incorporados à área de TI ou que fossem substituídos por analistas de TI que tiveram seus cargos "enriquecidos".

O incremento de competitividade provocou uma grande onda de processos radicais e contínuos de mudança (Wood Jr. e Caldas, 1995), o que influenciou significativamente a eliminação de muitas áreas e postos de trabalho de O\&M nas organizações no Brasil. Na maior parte dessas mudanças, a função e o profissional de O\&M mostraram-se incapazes de conduzir essas transformações em cada empresa ou instituição. Como conseqüência, a área e o profissional de O\&M tornaram-se eles próprios alvos dessas mudanças.

Por fim, há diversos fatores ligados à autodeterioração do O\&M tradicional: a postura arrogante de "interventor externo" que o O\&M tradicional tipicamente assumia, o anacronismo das práticas fordistas de "organização racional do trabalho" que

Figura 4 - Evolução da área comprada por área (excluindo informática)

IMPORTÂNCIA RELATIVA DOS ANÚNCIOS POR ÁREA

(Proporção dos anúncios de destaque por área (excluindo área de informática))

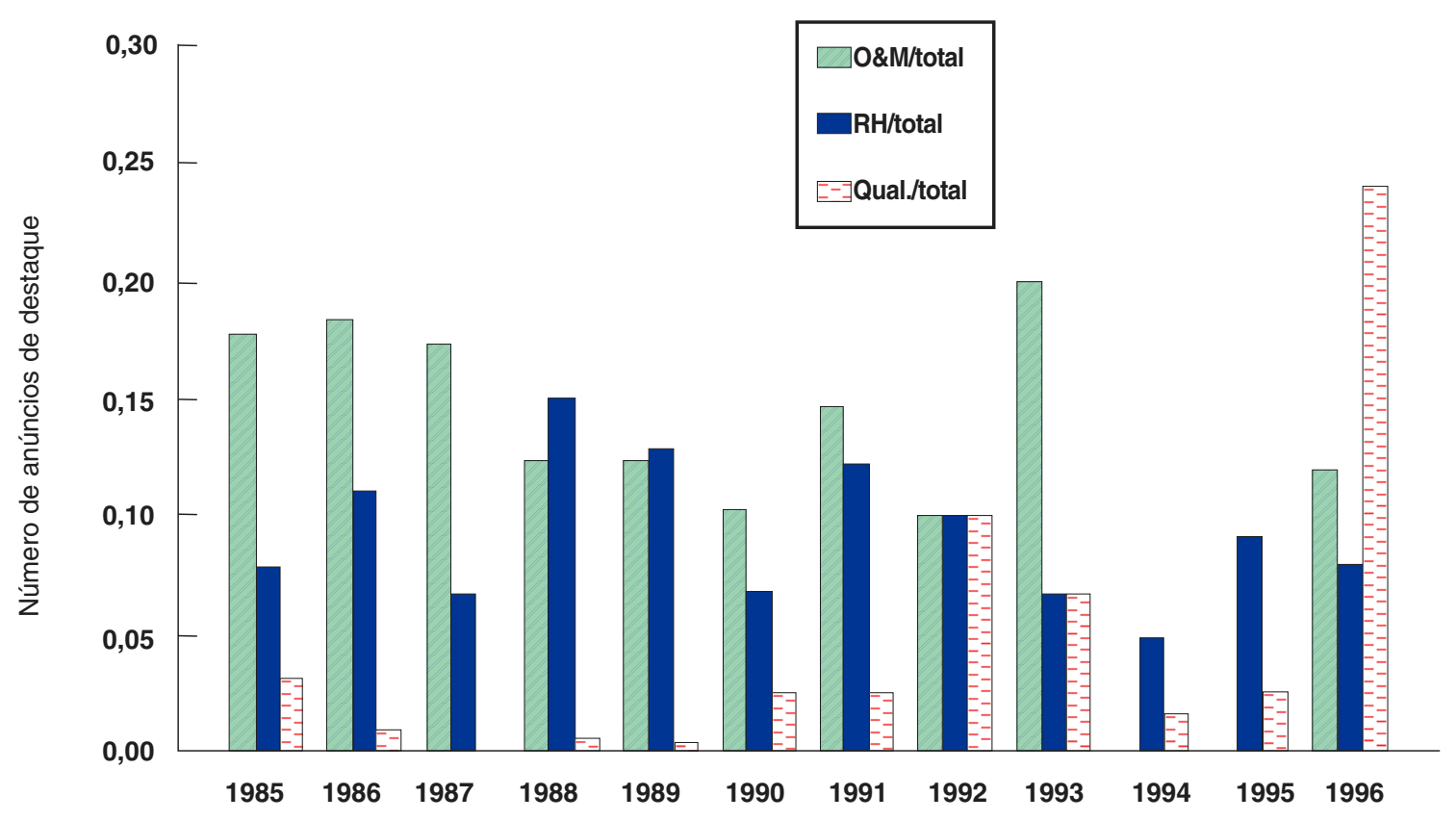


estavam na base do O\&M convencional, bem como a incapacidade do O\&M tradicional em adaptar-se a todas essas transformações discutidas em seu ambiente de atuação.

\section{O tipo de cargo ofertado}

\section{em O\&M tem sido cada vez}

\section{menos importante, e os anúncios}

\section{são cada vez menos destacados}

\section{em relação às demais áreas.}

Finalmente, cabe discutir por que, em meio a tantas transformações no seu contexto de atuação e em meio a tantas evidências da irreversibilidade de tais tendências, tantas áreas e profissionais de $0 \& M$ falharam em evoluir ou adaptar-se. Obviamente, tanto as práticas quanto a postura do O\&M tradicional não eram adequadas ao novo contexto organizacional. As mudanças ocorreram lenta, porém declarada e sistematicamente, na maioria das organizações, no mundo e no Brasil. Entretanto, em vez de acompanharem tais transformações e adaptarem-se, muitas áreas e profissionais de O\&M persistiram em práticas e comportamentos aceitáveis somente no antigo regime. Se compararmos o ambiente organizacional até os anos 70 com o dos anos 90, é preciso admitir que não foi apenas o contexto da função de O\&M que sofreu com as tremendas transformações acima descritas: poucas funções organizacionais ficaram incólumes às mudanças no ambiente empresarial. Ao que tudo indica, o que diferencia o O\&M é que, em muitas organizações, a função - e os seus profissionais sofreu um processo bem retratado por Gonçalves (1995): a transformação ocorreu com a lentidão necessária para que o pessoal de $O \& M$ não a percebesse.

\section{CONCLUSÕES}

Se aceita a representatividade da presente pesquisa quanto ao que ocorreu com a carreira de O\&M no Brasil desde 1985, parece possível estabelecer conjecturas razoáveis do destino da função e do profissional de Organização e Métodos nas organizações em nosso país.
No que tange à função e às atividades de $\mathrm{O} \& \mathrm{M}$, pode-se prever que, quanto mais organizações passarem a enfrentar as mesmas influências (ou "fatores condicionantes" sintetizados acima), maior deve ser o impacto no O\&M tradicional e maior deve ser a tendência de transformação na sua configuração.

A mudança nos modelos de gestão, embora possa tardar em alguns setores de atividade, regiões ou tipos de organização, parece ter ímpeto e força suficiente para minar os conceitos nos quais a convencional função de O\&M se embasou. A difusão desses novos modelos - seja por meio de novos entrantes nas organizações, seja via pacotes de intervenção ou ainda por meio de efeitos institucionalizantes da educação em massa de administração, das práticas de novos concorrentes e de ações governamentais - deve afetar significativamente as áreas de O\&M que ainda são sustentadas justamente pela ausência dessas práticas de gestão nos espaços organizacionais em que sobrevivem.

À medida que o incremento da competitividade atingir mais fortemente setores nos quais o O\&M tradicional sobrevive, as organizações devem tender a exigir nova configuração dessa função - por exemplo, para conduzir as mudanças ou para efetivamente contribuir no processo - e, caso tal expectativa seja frustada pela área de O\&M, devem tender a pressionar para eliminála, diluir suas atividades em outras funções mais adaptadas da organização e/ou passar para terceiros (como consultores) a execução das atividades de O\&M. Uma vez que o incremento de competitividade pode tardar a afetar alguns setores de atividade mais rápida e significativamente do que outros, é plausível que "ilhas" de estabilidade surjam para manter seguro o O\&M tradicional em algumas organizações ou mesmo em alguns conjuntos de organizações.

De todos os fatores que afetam as organizações e influenciam a transformação de O\&M, o avanço da Tecnologia de Informação (TI) parece ser aquele que mais deve acelerar o processo de transformação da função e das atividades de O\&M nas organizações em que a área ainda preserva seu perfil convencional. A aceleração do crescimento da indústria de informática, a difusão de seu uso para simplificação e racionalização das mais variadas organizações, bem como o incremento de sua acessibilidade a quase todo tipo de usuário nas empresas, devem tornar cada vez mais difícil a sobrevivência do O\&M tradicional. Onde ele ainda existir, é de se esperar forte pressão no sentido de subordinação da maioria de suas atividades à área de informática e, subseqüentemente, pressão para a eliminação 
ou diluição em outras áreas (RH, qualidade etc.) ou ainda terceirização do restante de suas atividades, que podem não justificar a manutenção do O\&M como área independente.

\section{O profissional de O\&M parece ter}

\section{perdido atratividade e prestígio}

\section{quando comparado ao de outras}

\section{áreas funcionais.}

Pela progressão aparentemente incontrolável de todos os fatores de influência nas organizações de hoje, é razoável prever que será difícil para áreas de O\&M convencionais resistir incólumes às pressões para sua extinção, diluição ou radical transformação nos próximos anos. Conseqüentemente, também é provável que a carreira de O\&M tenda a sofrer mudanças significativas em função do destino da função e das atividades de O\&M nas organizações.

No que se refere à carreira de Organizações e Métodos e em óbvia relação com o destino da função e de suas atividades, o mais provável é que vejamos cada vez mais o seu declínio como primeira opção profissional de jovens entrantes nas organizações. Dentre aqueles profissionais já na carreira, é de se esperar a queda progressiva no prestígio, nas oportunidades de ascensão e, conseqüentemente, o declínio de remuneração potencial ao longo do tempo. Novamente, as "ilhas" de estabilidade hoje existentes podem sustentar-se por muito tempo, mas a pesquisa apresenta diversas evidências de que essa estabilidade deve sofrer crescente pressão nos próximos anos, à medida que novas formas de gestão se popularizam, novas tecnologias tornam-se mais acessíveis e a competitividade é incrementada. Os resultados também indicam que futuros mais promissores para profissionais de O\&M devem atrair indivíduos da área para outras funções, em especial para informática, recursos humanos e qualidade, bem como para carreiras alternativas como consultoria e prestação de serviços externos.

É claro que os profissionais de O\&M não estão "condenados" à extinção ou à aposentadoria prematura. É verdade que, se o que ocorreu no passado do O\&M for um indicador de seu futuro, é provável que seja mais difícil para esses profissionais adiantaremse às mudanças do que adaptarem-se a elas, se e quando isso ocorrer. Nesse sentido, a presente pesquisa oferece indicações importantes sobre as alternativas dessa carreira na eventualidade de que muitos profissionais venham, como aqui previsto, a sofrer os reveses de mudanças na função de O\&M em que trabalham. Nessa eventualidade, a pesquisa mostra que eles tendem a migrar e que as áreas de informática, de recursos humanos e de qualidade tendem a ser as escolhas naturais dentro da organização, da mesma forma que a consultoria tende a ser uma possibilidade efetiva fora das fronteiras organizacionais. E, sem dúvida, a pesquisa sugere claramente que preparar-se para essas transformações - e para uma eventual migração de carreira - pode ser uma inteligente opção de empregabilidade para os profissionais de O\&M hoje atuantes nas organizações.

REFERÊNCIAS BIBLIOGRÁFICAS

GONÇALVES, José Ernesto Lima. Um novo O\&M para recuperar. RAE Light, São Paulo, v.2, n.3, p.22-7, maio/ jun. 1995.

MINTZBERG, Henry. Criando organizações eficazes: estruturas em cinco configurações. São Paulo: Atlas, 1995.

NOTAS

Este artigo baseia-se em pesquisa financiada pelo NPP Núcleo de Pesquisas e Publicações da EAESP/FGV
NADLER, David A., GERSTEIN, Marc S. Projetos de sistemas de trabalho de alto desempenho: como organizar pessoal, trabalho, tecnologia e informação. In: NADLER, David et al. Arquitetura organizacional: a chave para a mudança empresarial. Rio de Janeiro: Campus, 1994. p.95-114.
W00D JR., Thomaz, CALDAS, Miguel. Quem tem medo de eletrochoque? Identidade, terapias convulsivas e mudança organizacional. RAE-Revista de Administração de Empresas, São Paulo, v.35, n.5, p.13-21, set./out. 1995. intitulada "A evolução da função e da carreira de 0\&M no Brasil (1985-1997)".
1. 0 ano de 1997 não foi incluído porque, em virtude de 0 levantamento ter ocorrido no primeiro semestre daquele ano. nem todas as edições do jornal poderiam ser observadas. 